\title{
Modelling of Operating Conditions of Conduction Heat Transfer Mode Using Energy 2D Simulation
}

\author{
https://doi.org/10.3991/ijoe.v14i09.9116 \\ Saad S. Alrwashdeh \\ Mutah University, Al-Karak -Jordan \\ saad.alrwashdeh@mutah.edu.jo, saad_r1988@yahoo.com
}

\begin{abstract}
An energy transfers across a system boundary due to a temperature difference by the mechanism of inter-molecular interactions called conduction heat transfer. In the present work, a mathematical model and a simulation based on Energy 2D V 3.0.1 simulator are presented to study the effect of the conduction parameters: thermal conductivity, surface contact area, temperature difference and conduction distance on the heat transferred by the conduction mode.
\end{abstract}

Keywords-conduction mode, thermal conductivity, surface contact area, temperature difference, conduction distance

\section{Introduction}

Conductive heat transfer is widely used in several electronic equipment. The design of conductive systems has been approached by various methods, in which the optimization of heat transfer parameters is of particularly interest [1-8]. However, the interaction between the heat conduction mode parameters is becoming a challenging problem for designers.

Determining the effective thermal conductivity and total diffusivity of saturated and unsaturated porous media are the focus to goodly number of studies, which underlies the centrality of the property in both theoretical work and interpretation of experimental data. Temperature distributions in heated packed beds of spheres are used with solution of the inverse problem for transient heat transfer, and with a step change in the boundary heat flux, the effective conductivity may reach a value several times higher than at steady state [9].

Experimental investigations include the thermal conductivity of Kapton HN sheets at super fluid helium temperatures, the use of a novel cylindrical hot wire probe to determine the conductivity of biological tissue, and the determination of the role of moisture in the insulation effectiveness of certain insulations and building materials [10-12]. The effects of the temperature difference of the conduction is analyzed and presented. Experimental results are presented for boiling off silicon chips with micropin-fins [13]. The rate of heat flow between two objects is proportional to their difference in temperature. 
Laplace transforms are used to calculate transient heat flow through multilayer spherical structures [14]. Parallel computations are performed for lower and upper bounds of temperature in a conjugate heat transfer problem [15]. A domain decomposition method is described for three-dimensional boundary-element models in heat conduction [16]. The simulation of heat transfers and related processes is achieved by numerical solution of the governing partial differential equations.

In this research study, the temperature dependency of PV panel output performance was investigated in Amman-Jordan using Energy 3D V8.2.5 simulator.

\section{Conduction Heat Transfer}

Conduction is an energy transfer across a system boundary due to a temperature difference by the mechanism of inter-molecular interactions. Conduction needs matter and does not require any bulk motion of matter. The physical mechanism of conduction is most easily explained by considering a gas and using ideas familiar from the thermodynamics background. Considering a gas in which a temperature gradient exists, and assuming that there is no bulk, or macroscopic, motion. The gas may occupy the space between two surfaces that are maintained at different temperatures. It is associated the temperature at any point with the energy of gas molecules in proximity to the point. This energy is related to the random translational motion, as well as to the internal rotational and vibrational motions, of the molecules [17].

Fourier's law developed from observed phenomena rather than being derived from basic principles. Hence, we view the rate equation as a generalization based on much experimental evidence. For example, consider the steady-state conduction experiment of a cylindrical rod of known material is insulated on its lateral surface, while its end faces are maintained at different temperatures, with $\mathrm{T} 1>\mathrm{T} 2$. The temperature difference causes conduction heat transfer. We are able to measure the heat transfer rate $\mathrm{q}$ $(\mathrm{W})$, and we seek to determine how q depends on the following variables: $\Delta \mathrm{T}\left({ }^{\circ} \mathrm{C}\right)$, the temperature difference; $\Delta \mathrm{x}(\mathrm{m})$, the length; and $\mathrm{A}(\mathrm{m} 2)$, the cross-sectional area.

We might imagine first holding $\Delta \mathrm{T}$ and $\Delta \mathrm{x}$ constant and varying $\mathrm{A}$. If we do so, we find that $\mathrm{q}$ is directly proportional to A. Similarly, holding $\Delta \mathrm{T}$ and $\mathrm{A}$ constant, we observe that $\mathrm{q}$ varies inversely with $\Delta \mathrm{x}$. Finally, holding $\mathrm{A}$ and $\Delta \mathrm{x}$ constant, we find that $\mathrm{q}$ is directly proportional to $\Delta \mathrm{T}$. The collective effect is then

$q \propto A\left(\frac{\Delta T}{\Delta x}\right)$

In changing the material (e.g., from a metal to a wood), we would find that this proportionality remains valid. However, we would also find that, for equal values of $\mathrm{A}, \Delta \mathrm{x}$, and $\Delta \mathrm{T}$, the value of $\mathrm{q}$ would be smaller for the plastic than for the metal. This suggests that the proportionality may be converted to an equality by introducing a coefficient that is a measure of the material behavior. Hence, we write:

$q=k A\left(\frac{\Delta T}{\Delta x}\right)$ 
where $\mathrm{k}$, the thermal conductivity $(\mathrm{W} / \mathrm{m} . \mathrm{K})$ is an important property of the material. Evaluating

this expression in the limit as $\Delta \mathrm{x}$ approach to zero, we obtain for the heat rate

$$
q=-k A\left(\frac{\Delta T}{\Delta x}\right)
$$

\section{$3 \quad$ Energy 3D simulation}

Based on computational physics research, Energy2D is an interactive, visual $\mathrm{Mu}$ tiphysics simulation program that models all three modes of heat transferconduction, convection, and radiation, and their coupling with particle dynamics. Energy2D runs very quickly on most computers and eliminates the switches among preprocessors, solvers, and postprocessors typically needed to perform computational fluid dynamics simulations. It allows you to design "computational experiments" to test a scientific hypothesis or solve an engineering problem without resorting to complex mathematics.

\section{Simulation results and discussion}

Thermal conductivity $\mathrm{K}$ is the property of a material to conduct heat. Figure. 1 shows Energy 2D simulation result of the uses of different material: wood and metal with a heat source at $50{ }^{\circ} \mathrm{C}$. It is noted that the heat transfer through the metal can reach the steady state before the wood. The temperature in the vessel after the wood was $24.1{ }^{\circ} \mathrm{C}$ while it was $50{ }^{\circ} \mathrm{C}$ (Steady state) in the vessel after the metal.

The simulation shows that the temperature depends on the dimension. It is found that the temperature distribution can achieve the steady state situation in the large area faster than in the small area see figure. 2. The temperature using A.1 is 47.9 at the second vessel and 50 (steady state) using A.2. Overall, the amount of heat conducted, $\mathrm{Q}$, is proportional to the cross-sectional area, $\mathrm{A}$

The rate of heat flow between two objects is proportional to their difference in temperature. Based on the figure. 3 it is noted that the time required to achieve the steady state situation is same for two different temperature differences 100 and $50{ }^{\circ} \mathrm{C}$. Overall, the greater the difference in temperature between the two ends of the bar, the greater the rate of thermal energy transfer, so more heat is transferred. The heat, $\mathrm{Q}$, is proportional to the difference in temperature. 


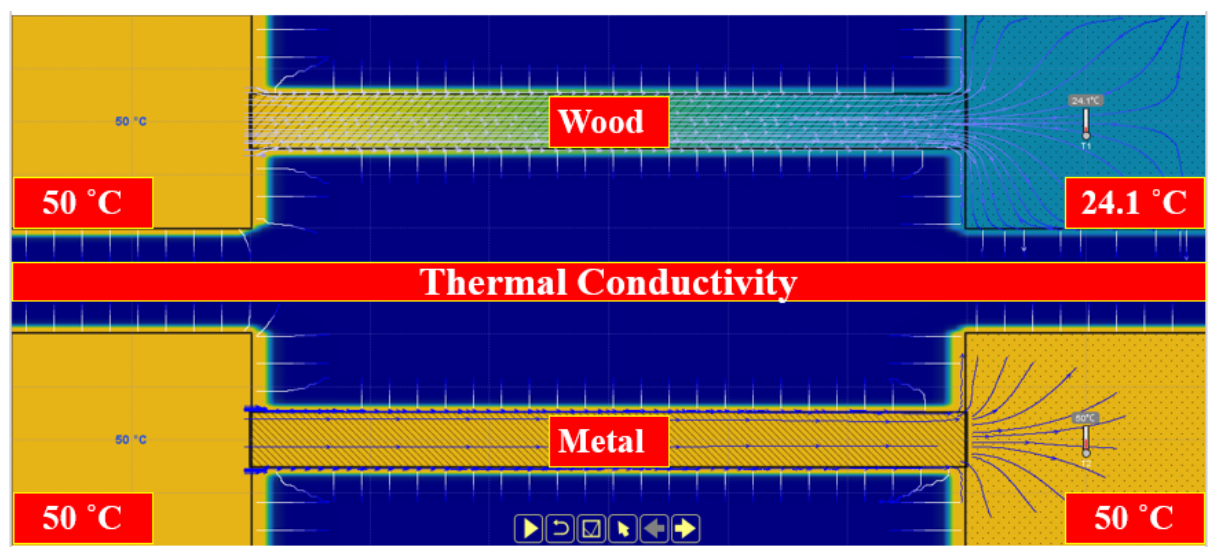

Fig. 1. Simulation result of different thermal conductivity

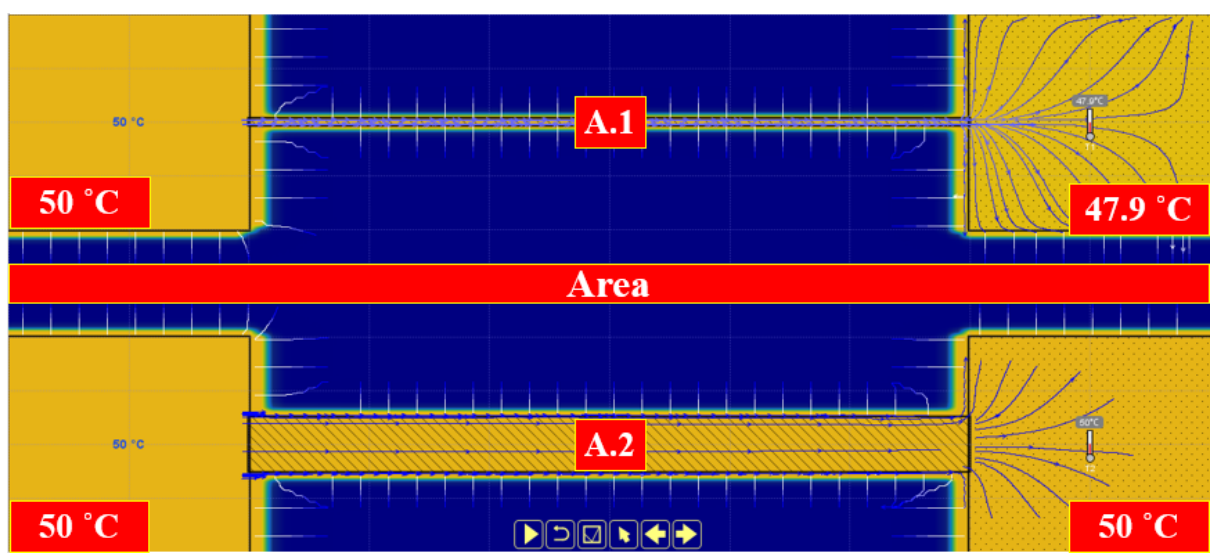

Fig. 2. Simulation result of different areas

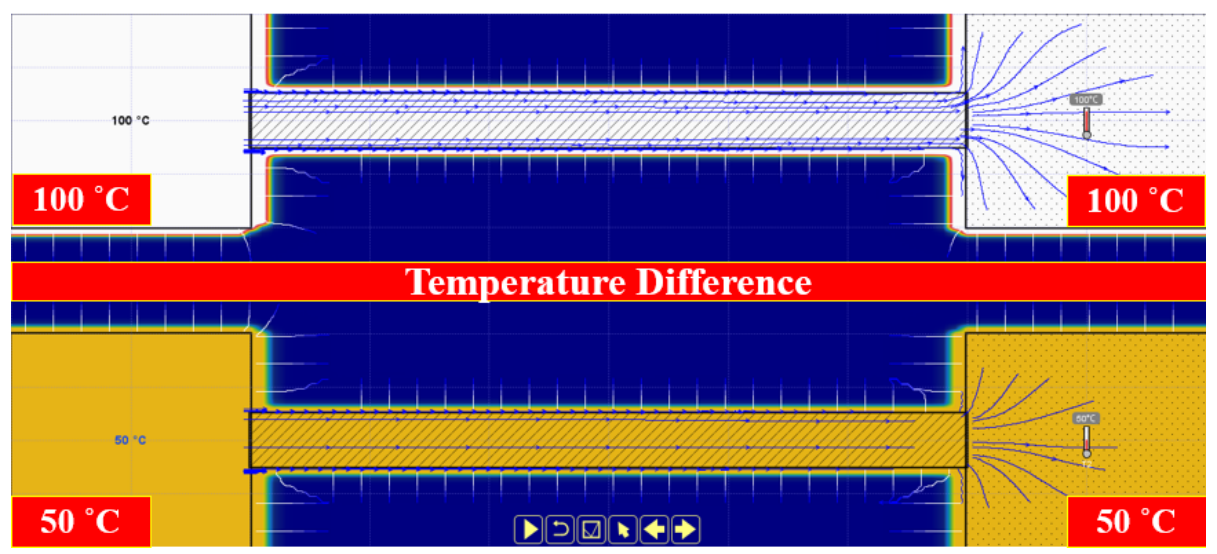

Fig. 3. Simulation result of temperature differences 


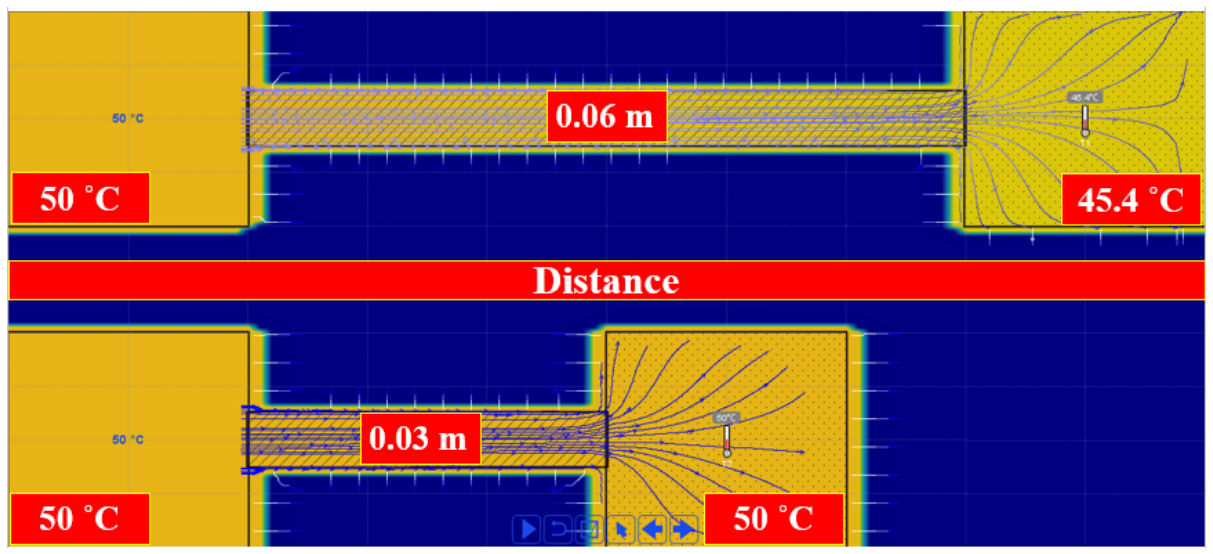

Fig. 4. Simulation result of conduction distance

The longer the distance, the less heat that will make it all the way through. Therefore, the conducted heat is inversely proportional to the distance of conduction see figure. 4.

Figure. 5 shows the interaction of the parameters effect the conduction heat transfer mode. Thermal conductivity of the used substance is a major issue as the thermal conductivity as well the cross-section area proportional to the amount of the heat transferred as it is noted in figure.5a that the metal reaches the steady state faster than the wood. Thus, the metal can transfer the heat efficient than the wood. Big cross section area component can reach the steady state faster than the small cross section area components see figure. 5b. Higher temperature difference means higher heat transfer amount as it is noted in figure. $5 \mathrm{c}$. The conduction distance inversely proportional to the amount of heat transfer as clearly seen in figure. $5 \mathrm{~d}$.

On the molecular level, the molecules near the heat source are heated and begin vibrating faster. They bounce off nearby molecules and cause them to vibrate faster. That increased bouncing is what heats a substance. Take in the consideration the different properties of the objects into account when we want to examine the conduction that takes place. for example, cross-sectional area and length, along with the temperature at different parts.

\section{Conclusion}

The interaction of the parameters of the amount of heat transferred by conduction in a given amount of time, $t$, down a length $\mathrm{L}$, where the cross-sectional area is A. Here, $\mathrm{k}$ is the material's thermal conductivity are studied. It is found from the simulation result that: 

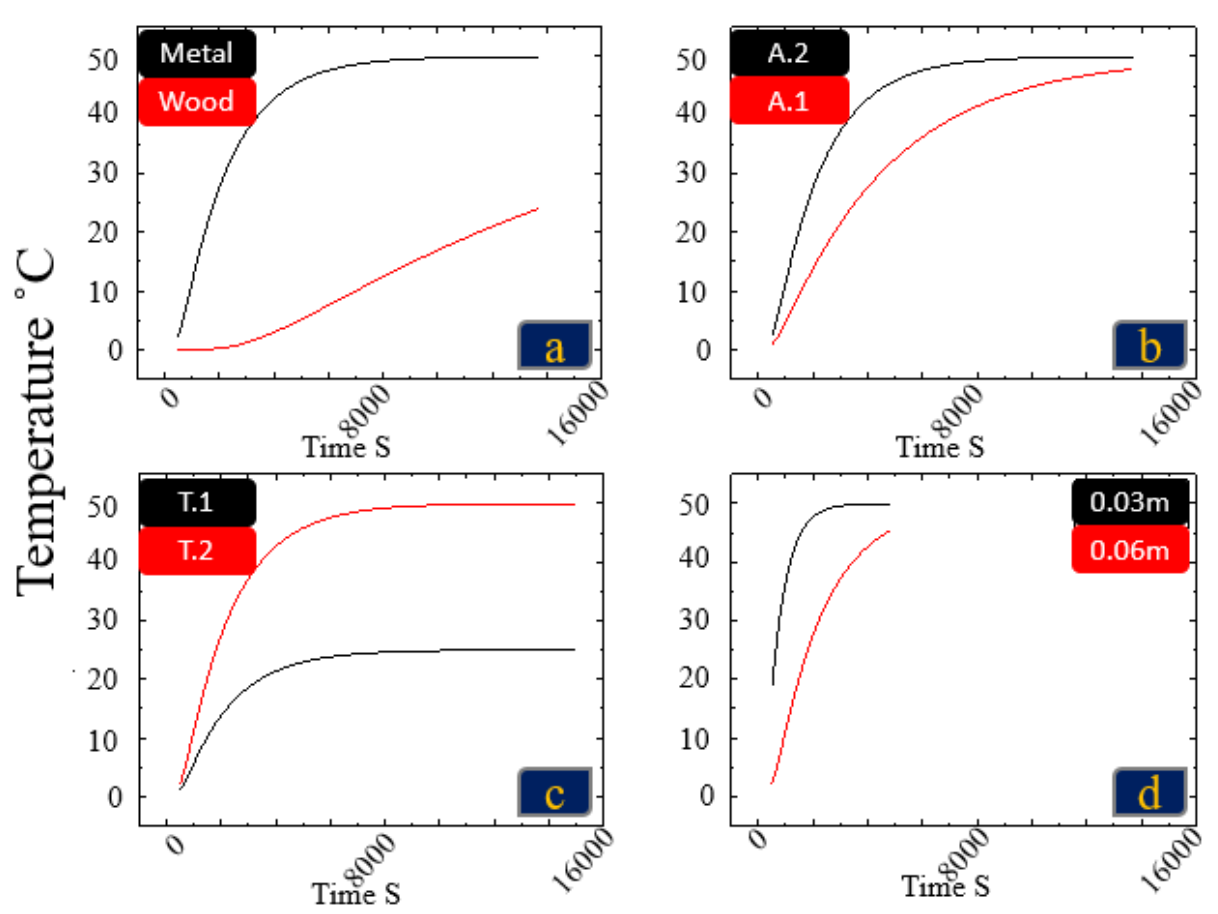

Fig. 5. Simulation result of heat conduction parameter interaction

The greater the difference in temperature between the two ends of the bar, the greater the rate of thermal energy transfer, so more heat is transferred. The heat, $\mathrm{Q}$, is proportional to the difference in temperature:

\section{$Q \alpha \Delta T$}

The amount of heat conducted, Q, is proportional to the cross-sectional area, A, like this:

\section{$Q \alpha A$}

The conducted heat is inversely proportional to the length:

$$
Q \alpha\left(\frac{1}{L}\right)
$$

The amount of heat transferred, Q, depends on the amount of time that passes:

$Q \alpha t$ 


\section{References}

[1] Mazloomi, A., et al., Optimization of highly conductive insert architecture for cooling a rectangular chip. International Communications in Heat and Mass Transfer, 2012. 39(8): p. 1265-1271. https://doi.org/10.1016/j.icheatmasstransfer.2012.06.010

[2] Li, Y., P. Wei, and H. Ma, Integrated optimization of heat-transfer systems consisting of discrete thermal conductors and solid material. International Journal of Heat and Mass Transfer, 2017. 113: p. 1059-1069. https://doi.org/10.1016/j.ijheatmasstransfer.2017. 06.018

[3] Xia, Z.-Z., et al., Bionic Optimization of Heat Transport Paths for Heat Conduction Problems. 2004. 11(2): p. 119-132.

[4] Daneshi, M., M. Zare, and M. Reza Salimpour, Micro- and Nanoscale Conductive TreeStructures for Cooling a Disk-Shaped Electronic Piece. Journal of Heat Transfer, 2013. 135(3): p. 031401-031401-10. https://doi.org/10.1115/1.4007903

[5] Lorenzini, G., C. Biserni, and L.A.O. Rocha, Constructal design of non-uniform X-shaped conductive pathways for cooling. International Journal of Thermal Sciences, 2013. 71: p. 140-147. https://doi.org/10.1016/j.ijthermalsci.2013.04.021

[6] Saad S. Alrwashdeh, et al., Improved Performance of Polymer Electrolyte Membrane Fuel Cells with Modified Microporous Layer Structures. Energy Technology, 2017. 5(9): p. 1612-1618. https://doi.org/10.1002/ente.201700005

[7] Alrwashdeh, S.S., et al., Neutron radiographic in operando investigation of water transport in polymer electrolyte membrane fuel cells with channel barriers. Energy Conversion and Management, 2017. 148: p. 604-610. https://doi.org/10.1016/j.enconman.2017.06.032

[8] Alrwashdeh, S.S., et al., In Operando Quantification of Three-Dimensional Water Distribution in Nanoporous Carbon-Based Layers in Polymer Electrolyte Membrane Fuel Cells. ACS Nano, 2017. 11(6): p. 5944-5949. https://doi.org/10.1021/acsnano.7b01720

[9] Polesek-Karczewska, S., Effective thermal conductivity of packed beds of spheres in transient heat transfer. Heat and Mass Transfer, 2003. 39(5): p. 375-380. https://doi.org/10.1007/s00231-002-0343-6

[10] Consalvi, J.L., B. Porterie, and J.C. Loraud, ON THE USE OF GRAY ASSUMPTION FOR MODELING THERMAL RADIATION THROUGH WATER SPRAYS. Numerical Heat Transfer, Part A: Applications, 2003. 44(5): p. 505-519. https://doi.org/10.1080/ 713838254

[11] Coelho, P.J., P. Perez, and M. El Hafi, BENCHMARK NUMERICAL SOLUTIONS FOR RADIATIVE HEAT TRANSFER IN TWO-DIMENSIONAL AXISYMMETRIC ENCLOSURES WITH NONGRAY SOOTING MEDIA. Numerical Heat Transfer, Part B: Fundamentals, 2003. 43(5): p. 425-444. https://doi.org/10.1080/713836240

[12] Wiedenhoefer, J.F. and R.D. Reitz, A MULTIDIMENSIONAL RADIATION MODEL FOR DIESEL ENGINE SIMULATION WITH COMPARISON TO EXPERIMENT. Numerical Heat Transfer, Part A: Applications, 2003. 44(7): p. 665-682. https://doi.org/10.1080/716100522

[13] Wei, J., et al., Boiling Heat Transfer Enhancement by Using Micro-pin-finned Surface for Electronics Cooling. Microgravity Science and Technology, 2009. 21(1): p. 159-173. https://doi.org/10.1007/s12217-009-9137-5

[14] Alhama, F., J. Zueco, and C.F. González Fernández, An Inverse Determination of Unsteady Heat Fluxes Using a Network Simulation Method. Journal of Heat Transfer, 2003. 125(6): p. 1178-1183. https://doi.org/10.1115/1.1597614 
[15] Cheng, Z. and M. Paraschivoiu, Parallel computations of finite element output bounds for conjugate heat transfer. Finite Elements in Analysis and Design, 2003. 39(7): p. 581-597. https://doi.org/10.1016/S0168-874X(02)00129-4

[16] Divo, E., A.J. Kassab, and F. Rodriguez, PARALLEL DOMAIN DECOMPOSITION APPROACH FOR LARGE-SCALE THREE-DIMENSIONAL BOUNDARY-ELEMENT MODELS IN LINEAR AND NONLINEAR HEAT CONDUCTION. Numerical Heat Transfer, Part B: Fundamentals, 2003. 44(5): p. 417-437. https://doi.org/10.1080/ 716100489

[17] Frank P. Incropera, D.P.D., Fundamentals of Heat and Mass Transfer. 7 ed. 2011, USA: Wiley.

\section{$7 \quad$ Author}

Dr. Ing. Saad S. Alrwashdeh is an Assistant Professor of Renewable Energy at Mutah University in Jordan. He received his doctorate in Renewable Energy and Nuclear Imaging from Technischen Universität Berlin in Germany. His research interests include the Heat Transfer and the Fluid Mechanics.

Article submitted 28 June 2018. Resubmitted 14 July 2018. Final acceptance 15 July 2018. Final version published as submitted by the author. 